\title{
Prevalence of insulin resistance and risk of diabetes mellitus in HIV-infected patients receiving current antiretroviral drugs
}

\author{
Susana Araujo, Sara Bañón, Isabel Machuca, Ana Moreno, María J Pérez-Elías and \\ José L Casado
}

Department of Infectious Diseases, Ramon y Cajal Hospital, Cra. Colmenar, Km 9.1, 28034 Madrid, Spain
Correspondence should be addressed to J L Casado

Email

jose.casado

@salud.madrid.org

\begin{abstract}
Objective: HIV-infected patients had a higher prevalence of insulin resistance (IR) and risk of diabetes mellitus (DM) than that observed in healthy controls, but there are no data about the current prevalence considering the changes in HIV presentation and the use of newer antiretroviral drugs.

Design: Longitudinal study which involved 265 HIV patients without DM, receiving first $(n=71)$ and advanced lines of antiretroviral therapy $(n=194)$.

Methods: Prevalence of IR according to clinical and anthropometric variables, including dual X-ray absorptiometry (DXA) scan evaluation. IR was defined as homeostasis model assessment of IR $\geq 3.8$. Incident DM was assessed during the follow-up. Results: First-line patients had a short time of HIV infection, less hepatitis C virus coinfection, and received mainly an efavirenz-based regimen. Overall, the prevalence of IR was $21 \%$ (55 patients, $6 \%$ in first-line, $27 \%$ in pretreated). In a logistic regression analysis, significant associations were found between the waist/hip circumference ratio (RR 10; 95\% $\mathrm{Cl} 1.66-16$; $P<0.01$, per unit), and central fat in percentage (RR 1.08; $95 \% \mathrm{Cl} 1.01-1.17 ; P=0.04$, per unit) as evaluated by DXA, and IR. During 770.8 patient-years, DM was diagnosed in $8 \%$ (22 patients), mostly in pretreated patients ( $10 \mathrm{vs} 4 \% ; P=0.1)$. Thus, the overall rate of incident DM was 2.85 per 100 person-years, mostly in previous IR (10.39 vs $0.82 / 100$ person-years; $P=0.01)$. Conclusions: A lower prevalence of IR is observed in the current HIV-infected patients with fewer risk factors and receiving newer antiretroviral drugs. IR continues to identify patients at high risk for developing DM in the short term.
\end{abstract}

\section{Introduction}

The introduction of highly active antiretroviral therapy (HAART) has changed the course of HIV infection, increasing life expectancy (1), but on the other hand making more prevalent diseases such as osteoporosis, neurocognitive impairment, renal disease, and cardiovascular events (2). Among these associated comorbidities, HIV-infected patients frequently experience metabolic complications such as insulin resistance (IR), increasing the risk of diabetes mellitus (DM) (3). Rates of DM among HIV-positive patients have been reported to range between 2 and $14 \%(4,5,6)$, and in an aging HIV-positive population, the prevalence of $\mathrm{DM}$ is expected to continue to increase.

Indeed, from the beginning of the HIV epidemic, and particularly after the introduction of HAART, the prevalence of IR has been reported in up to $35-63 \%$ of patients, much higher than in uninfected control populations $(6,7,8,9)$. IR in HIV patients has been associated with an increased risk of cardiovascular risk and mortality, and particularly with the development of DM, several folds higher in case of IR $(5,6,7)$. (c) 2014 European Society of Endocrinology Printed in Great Britain
Published by Bioscientifica Ltd. 
This high prevalence in a younger population has been attributed to the presence of additional risk factors, such as HIV itself, vitamin D deficiency, coinfection with hepatitis $\mathrm{C}$ virus (HCV), and particularly as a possible adverse effect of different antiretroviral drugs (4, 10, 11, 12 , 13). This fact is particularly important as the HIV therapeutic arsenal continues to change with the development of newer drug classes and agents within existing drug classes, and therefore, the use of drugs with a lower causal role could change the prevalence and consequences of this complication. Drugs such as lopinavir, indinavir, stavudine (d4T), didanosine (ddI), and zidovudine (AZT) have been associated with IR $(14,15)$, but their use has markedly decreased during the last years.

Thus, hypothetically, changes in HIV therapy could have a direct repercussion on metabolic alterations, such as IR and DM, avoiding or delaying its emergence in recently treated patients, and decreasing its prevalence in largely pretreated cases. While this is plausible, the mechanisms of dysglycemia appear to be multifactorial, both HAART-dependent and HAART-independent, and there are few data confirming that the use of the current antiretroviral drugs is beneficial to HIV patients in terms of insulinemia or hyperglycemia.

Keeping this idea in mind, we investigated the rate and causes of IR and the risk of developing DM in currently treated HIV-infected patients in two different populations attending our unit: patients receiving advances lines of therapy, and patients in a first-line regimen.

\section{Patients and methods}

This was a prospective cohort study of HIV-positive patients consecutively attending our HIV unit between December 2010 and December 2011. The inclusion criteria were that patients must be over 18 years of age and be receiving antiretroviral treatment. Pregnant women, patients with advanced cirrhosis (Child-Pugh class B-C), daily alcohol intake, those receiving therapies that could alter blood glucose or insulin levels (corticosteroids, chemotherapy, or megestrol acetate), or those with a prior diagnosis of DM or receiving hypoglycemic treatments were excluded. Duration of follow-up spanned from inclusion to December 2013. The study was approved by our IRB and all patients gave informed consent.

\section{Variables}

At inclusion visit, information was collected from patients' charts and during patient interviews. Variables collected for patients included socio-demographic aspects (age, sex, risk practice for HIV infection), and clinical variables (time of HIV infection, CDC-stage, CD4 + nadir, peak HIV RNA level, HCV coinfection, antiretroviral treatment, and current and total time on therapy). Weight, height, and circumferences of waist and hip were measured as previously published. A venous blood sample was drawn after a 12-h overnight fast for determination of HIV-related parameters (CD4+ lymphocyte count and HIV load). Also, patients were screened for $\mathrm{HCV}$ coinfection (if not available at history), DM (fasting glucose), insulin (immunoassay, Immulite 2000, Siemens Healthcare Diagnostics, NY, USA), and vitamin D status (serum determination of 25 dihydroxyvitamin D) by enzymoimmunoassay (Architect i2000, Abbott Diagnostics). Blood analysis, including fasting glucose, was repeatedly obtained every 3-4 months as part of routine follow-up of the patients. After inclusion visit, a whole-body dual energy X-ray absorptiometry (DEXA) measurement was performed on all study subjects, using a Hologic QDR-4500A (Hologic, Inc., Bedford, MA, USA). The DEXA scans were assessed with a dedicated scanner and technologist. Routine daily quality control and calibration procedures were performed according to recommendations. The DEXA provided determinations in grams and percent fat for total body, body subregions such as trunk, arms, and legs, and a central abdominal region. We calculated the fat mass ratio (FMR) as the ratio of the percentage of the trunk fat mass to the percentage of the lower limb fat mass (percentage of the trunk fat mass/ percentage of the lower limb fat mass) (16).

\section{Definitions}

BMI was calculated as weight divided by height squared $\left(\mathrm{kg} / \mathrm{m}^{2}\right)$. IR was defined as a homeostasis model assessment of IR (HOMA-IR) value $>3.8$ (homeostatic model assessment-IR) calculated as the ratio between fasting insulin $(\mu \mathrm{U} / \mathrm{l}) \times$ fasting glucose $(\mathrm{mg} / \mathrm{dl}) / 405$ (17). This ratio has shown a very good correlation with measurements of IR by other methods (18), allowing for comparison between studies. Incident DM was considered to have occurred at the first follow-up visit after the index visit at which a confirmed value of fasting glucose was $\geq 126 \mathrm{mg} / \mathrm{dl}$, or anti-diabetic medication use was reported (19). HCV coinfection was defined as the presence of $\mathrm{HCV}$-positive serology and positive PCR for HCV RNA.

\section{Statistical analyses}

The main outcome measure was the prevalence and causes of IR, overall and according to line of HAART. Continuous 
variables were compared using the Student's $t$-test for normal distribution and the Mann-Whitney $U$ test otherwise. Categorical variables were analyzed with the $\chi^{2}$ test or Fisher's test, when applicable. Bivariate correlations and multivariate linear regression analysis were used to identify factors associated with higher insulinemia. A logistic regression analysis was performed with HOMA-IR $>3.8$ as dependent variable. Thereafter, DM incidence rate was calculated by dividing number of events by person time at risk. Kaplan-Meier estimates of time to DM were produced and stratified by IR. Data were censored on December 2013 for all subjects who reached this date without developing DM. A $P$ value $<0.05$ was considered to be statistically significant.

\section{Results}

A total of $280 \mathrm{HIV}$-infected patients were evaluated. Eleven were excluded due to discontinuation of the regimen at inclusion visit, and four because of a previous diagnosis of DM. The demographic and clinical characteristics of the 265 patients finally included (65, $25 \%$ women), according to line of antiretroviral therapy, are shown in Table 1. Mean age was 43.9 years (interquartile range, IQR, 39-49), mean BMI was $23.9 \mathrm{~kg} / \mathrm{m}^{2}$, and $107(40 \%)$ were coinfected with HCV. The prevalence of vitamin D deficiency $(<20 \mathrm{ng} / \mathrm{ml})$ was $57 \%$. The median duration of HIV infection was 181.5 months, while the cumulative time on HAART was 120.5 months. A total of 141 patients received ART based on non-nucleoside analogs (54\%), while 119 (45\%) received protease inhibitors (PI).

As expected, there were significant differences in baseline characteristics between first-line and pretreated patients, both in age and risk practices, and naturally in duration of HIV infection or type and time on antiretroviral therapy. Pretreated patients were older, they had a higher prevalence of HCV coinfection (51 vs $11 \%$ ), and had a higher duration of HIV infection and length of HAART. Noteworthy, no significant difference was observed in mean BMI, or vitamin D deficiency. Likewise, the use of drugs was different, with a predominance of

Table 1 Baseline characteristics of the 265 patients included and according to line of therapy. Values are expressed as median (IQR), unless otherwise specified.

\begin{tabular}{l}
\hline Variables \\
\hline Mean age (years, IQR) \\
Gender, male \\
Risk factors \\
IDU \\
MSM \\
Mean BMI $\left(\mathrm{kg} / \mathrm{m}^{2}\right)$ \\
Nadir CD4 $+\left(\mathrm{cells} / \mathrm{mm}^{3}\right.$ ) \\
Pretherapy HIV RNA level \\
(log copies/ml) \\
Time of HIV infection (months) \\
Current CD4+ (cells/mm ${ }^{3}$ ) \\
NNRTI \\
PI \\
Other \\
Time on current HAART \\
Cumulative time on HAART \\
(months) \\
HCV coinfection \\
Mean vitamin D (ng/ml) \\
Deficiency (<20) \\
Anthropometric/DXA measures \\
Waist (cm) \\
Waist/hip ratio \\
Trunk fat (kg) \\
Trunk fat (\%) \\
Total fat (\%) \\
Fat mass ratio \\
(a)
\end{tabular}

\begin{tabular}{c}
\hline Overall $(n=265)$ \\
\hline $43.9(39-49)$ \\
$200(75)$ \\
$106(40)$ \\
$101(38)$ \\
$23.9(21.5-25.9)$ \\
$217(107-331)$ \\
$4.9(4.22-5.3)$ \\
$181.5(81.8-246.2)$ \\
$347(211-518)$ \\
$141(54)$ \\
$119(45)$ \\
$5(1)$ \\
$48.1(31.6-50.2)$ \\
$120.5(48.6-188)$ \\
$107(40)$ \\
$20.3(12.7-25.4)$ \\
$(57)$ \\
$90.8(84-98)$ \\
$0.92(0.86-0.97)$ \\
$10.7(6.9-13.2)$ \\
$29.1(23.1-34.8)$ \\
$28.2(23.1-32.9)$ \\
$1.35(0.99-1.66)$ \\
\end{tabular}

\begin{tabular}{c} 
First line $(n=71,27 \%)$ \\
\hline $37.8(31-44)$ \\
$60(85)$ \\
$9(13)$ \\
$47(66)$ \\
$24.2(21.6-26.4)$ \\
$301(222-424)$ \\
$4.7(4.2-5.1)$ \\
$44.6(30.2-89.9)$ \\
$322(222-424)$ \\
$61(86)$ \\
$10(14)$ \\
- \\
$40.2(24.3-49.4)$ \\
$40.2(24.3-49.4)$ \\
$8(11)$ \\
$18.7(12-25.4)$ \\
$(64)$ \\
$88.3(81.7-97)$ \\
$0.89(0.84-0.95)$ \\
$10.8(6.6-13.2)$ \\
$27.3(21.5-34.1)$ \\
$27.4(22.8-32.2)$ \\
$1.16(0.95-1.35)$ \\
\end{tabular}

\begin{tabular}{c}
\hline Pretreated $(n=194,73 \%)$ \\
\hline $46.2(42-50)$ \\
$140(72)$ \\
$97(50)$ \\
$54(28)$ \\
$23.7(21.5-25.8)$ \\
$170(75-291)$ \\
$5(4.2-5.3)$ \\
$209.6(158.3-252.7)$ \\
$379(200-561)$ \\
$80(41)$ \\
$109(56)$ \\
$5(3)$ \\
$49.2(38.9-50.4)$ \\
$176.1(127.4-203)$ \\
$99(51)$ \\
$20.9(13.1-25.8)$ \\
$(55)$ \\
$91.7(85-99)$ \\
$0.93(0.87-0.98)$ \\
$10.6(7.1-13.5)$ \\
$28.5(23.1-33.2)$ \\
$28.5(23.1-33.2)$ \\
$1.43(1-1.79)$ \\
\end{tabular}

\begin{tabular}{c}
\hline $\boldsymbol{P}$ value \\
\hline$<0.01$ \\
0.039 \\
$<0.01$ \\
\\
0.27 \\
$<0.01$ \\
0.77 \\
$<0.01$ \\
0.02 \\
$<0.01$ \\
\\
$<0.01$ \\
$<0.01$ \\
$<0.01$ \\
0.14 \\
\\
$<0.01$ \\
0.78 \\
0.03 \\
0.31 \\
$<0.01$ \\
\hline
\end{tabular}

IQR, interquartile range; IDU, intravenous drug users; MSM, men having sex with men; NNRTI, non-nucleoside reverse transcriptase inhibitors; PI, protease inhibitors; HAART, highly active antiretroviral therapy; DXA, dual X-ray absorptiometry. 
PI in pretreated patients (14 vs 56\%), while most first-line patients received non-nucleoside analogs (86 vs $41 \%$ ). Specifically, DRV or ATV was primarily used in pretreated patients (Table 2). Nucleoside reverse transcriptase inhibitors (NRTIs) were mainly tenofovir plus emtricitabine, or abacavir plus lamivudine. No patient received therapy with d4T, ddI, or AZT at inclusion, although 72 and $64 \%$ of pretreated patients had received AZT or d4T in the previous current regimen.

A dual X-ray absorptiometry (DXA) scan was performed a median time of 59 days after inclusion (3-184). Regarding anthropometric measures, patients largely pretreated had a higher waist/hip circumference ratio and greater percentage of fat accumulation in trunk, despite similar kilograms of fat in trunk. Also, FMR was significantly higher in pretreated patients.

Of note, the current use of PI was not associated with a greater percentage of fat accumulation (28.9 vs 29.1; $P=0.4)$, or FMR (1.33 vs $1.38 ; P=0.43)$. However, cumulative time on HAART including PIs showed a weak but significant correlation with FMR $(r=0.37 ; P<0.01)$ and waist/hip ratio $(r=0.21 ; P=0.02)$, and not with trunk fat in grams or percentage.

\section{Insulin resistance}

At study entry, fasting glucose was $96.4 \mathrm{mg} / \mathrm{dl}$ (88-103), similar in pretreated and first-line patients, and independent of antiretroviral regimen. Mean insulinemia was
$12.8 \mu \mathrm{U} / 1$ (3.2-14.8), significantly higher in the group of pretreated patients (Table 2). Insulinemia was correlated with time of HIV infection $(r=0.2 ; P<0.01)$, HCV coinfection $(r=0.33 ; P<0.01)$; liver fibrosis degree $(r=0.36 ; P<0.01)$, triglycerides level $(r=0.35 ; P<0.01)$, waist circumference $(r=0.17 ; P=0.03)$, waist/hip ratio $(r=0.19 ; P=0.01)$, percentage of trunk fat $(r=0.18$; $P<0.01)$, FMR $(r=0.26 ; P<0.01)$, and higher baseline HIV RNA level $(r=-0.17 ; P=0.005)$, with a trend in association with age $(r=0.11 ; P=0.07)$, BMI $(r=0.1$; $P=0.09)$, trunk fat in grams $(r=0.11 ; P=0.08)$, total body fat $(r=0.11 ; P=0.07)$, and lower nadir CD4 + count $(r=-0.11 ; P=0.05)$. In a linear regression analysis, both HCV coinfection ( $\beta$ coefficient, $0.19 ; P=0.01$ ) and FMR in DXA $(\beta 0.24 ; P<0.01)$ were significantly associated with higher levels of insulinemia.

Overall, 21\% of patients had IR as defined (HOMA-IR $>3.8$ ). This result showed few changes according to sex (19 vs $26 \%$ in females; $P=0.23$ ), although there were significant differences by age ( 45.7 vs $43.2 ; P=0.056)$. Thus, the prevalence of IR was higher in each age decade (Fig. 1), ranging from 5\% for $<30$ years to $30 \%$ in patients over 60 years of age. Strikingly, the prevalence was $6 \%$ (four patients) in first-line patients, compared with $27 \%$ in pretreated patients.

In a univariate analysis (Table 3), IR was related to higher BMI, duration of HIV infection, total time on antiretroviral therapy, HCV coinfection, greater abdominal waist circumference, and increased waist/hip ratio

Table 2 Antiretroviral regimen, mean insulinemia and insulin resistance according to line of therapy. Values are expressed as mean (IQR, interquartile range).

\begin{tabular}{|c|c|c|c|c|c|}
\hline \multirow[b]{2}{*}{ Variables } & \multirow{2}{*}{$\begin{array}{l}\text { No. of cases } \\
\text { (first line/Pretx) }\end{array}$} & \multicolumn{2}{|c|}{ Insulinemia } & \multicolumn{2}{|c|}{ Insulin resistance } \\
\hline & & First line & Pretreated & First line & Pretreated \\
\hline Overall & 71/194 & $6.84(2-7)$ & $14.1(4.5-17.4)$ & $4(6 \%)$ & $52(27 \%)$ \\
\hline \multicolumn{6}{|l|}{ NNRTIs } \\
\hline Efavirenz & $56 / 41$ & $7.27(2-7.5)$ & $11.5(4.3-17.8)$ & $4(7 \%)$ & $7(17 \%)$ \\
\hline Nevirapine & $3 / 29$ & $3.87(2-4.8)$ & $10.5(2.5-9.4)$ & 0 & $7(24 \%)$ \\
\hline Etravirine & $2 / 10$ & $2.93(2.5-3)$ & $18.5(4.2-23.3)$ & 0 & $2(20 \%)$ \\
\hline \multicolumn{6}{|l|}{ Pls } \\
\hline Atazanavir & $0 / 45$ & - & $14.2(3-19.2)$ & - & $14(31 \%)$ \\
\hline Darunavir & $3 / 29$ & $5.7(3.3-6)$ & $14.8(7.8-16.8)$ & 0 & $8(28 \%)$ \\
\hline FosAPV & $1 / 10$ & 4.4 & $14(7-15.2)$ & 0 & $2(20 \%)$ \\
\hline Lopinavir & $6 / 25$ & $5.5(2-11.3)$ & $19.1(2.7-22.3)$ & 0 & $9(36 \%)$ \\
\hline \multicolumn{6}{|l|}{ TDF } \\
\hline Plus PI & $9 / 68$ & $6.55(2-12.3)$ & $14.5(4.8-22)$ & 0 & $20(29 \%)$ \\
\hline Plus NNRTI & $61 / 70$ & $6.97(2-7)$ & $12.4(4.1-15)$ & $4(7 \%)$ & $13(19 \%)$ \\
\hline$A B C$ & $1 / 56$ & 2 & $15.8(4.2-17.6)$ & 0 & $18(33 \%)$ \\
\hline Raltegravir & $0 / 4$ & - & $15.3(9-26.3)$ & - & $1(25 \%)$ \\
\hline
\end{tabular}

NNRTIs, non-nucleoside reverse transcriptase inhibitors; PI, protease inhibitors; Pretx, pretreated; APV, amprenavir; TDF, tenofovir; ABC, abacavir.

www.eje-online.org 


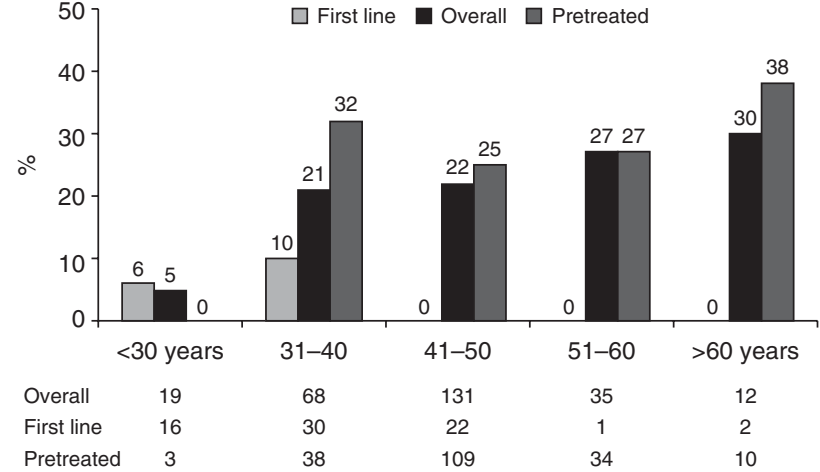

\section{Figure 1}

Prevalence of insulin resistance according to line of antiretroviral treatment and age strata.

(0.98 vs $0.9 ; P<0.01)$. There was no difference in the rate of IR based on plasma vitamin D levels, pretreatment CD4 + nadir or HIV RNA level, and also it was not related to baseline cholesterol, LDL-C, or HDL-C levels, but was related to plasma triglycerides at inclusion (195.8 vs $134.9 \mathrm{mg} / \mathrm{dl} ; P<0.01)$. In the whole-body DXA, performed an average of 2 months after inclusion, IR was observed in the presence of increased trunk fat $(12.8 \mathrm{vs} 10.1 \mathrm{~kg}$; $P=0.03)$, trunk fat percentage $(33.2$ vs $27.9 \% ; P<0.01)$, total body fat $(31.7$ vs $27.4 \% ; P<0.01)$, and trunk fat/ limb-fat ratio (FMR, 1.59 vs $1.28 ; P<0.01)$. Also, there were differences in prevalence of IR for cumulative ART treatment time (4602 vs 3478 days; $P=0.01$ ), and for patients receiving PIs vs NNRTIs (28 vs $14 \%$; relative risk $2.32,95 \%$ CI $1.24-4.44 ; P<0.01)$.

In a multivariate logistic regression analysis, significant associations were found between the waist/hip circumference ratio (RR 10; 95\% CI 1.66-16; $P<0.01$, per unit higher) and central fat in percentage (RR 1.08; 95\% CI 1.01-1.17; $P=0.04$, per \% higher) as evaluated by DXA, and HOMA-IR. These associations remained significant after adjustments for age, gender, BMI, PI or NNRTI use, CD4 cell count and HIV RNA level, and cumulative time on HAART. On the other hand, no significant association was found between IR and peripheral fat, FMR, or central fat in kilograms. As an association between PI use, HCV infection, cumulative time on HAART, and fat accumulation could be observed, we repeated the model excluding anthropometric measures. In this analysis, BMI (RR 1.13/kg per $\mathrm{m}^{2} ; P=0.04$ ) and $\mathrm{HCV}$ coinfection (RR 2.46; $P=0.04$ ) were related with IR, and there was a trend in association with cumulative time on PI (RR 1.01; 95\% CI 0.98-1.01 per month; $P=0.08$ ), but not with current PI use.

\section{Consequences of IR}

In a median follow-up of 35.2 months after insulinemia determination (19.7-40.9; 770.8 patient-years on

Table 3 Factors associated with insulin resistance (HOMA $\geq 3.8$ ).

\begin{tabular}{|c|c|c|c|c|c|c|}
\hline \multirow[b]{2}{*}{ Variable } & \multicolumn{3}{|c|}{ Univariate analysis } & \multicolumn{3}{|c|}{ Multivariate analysis } \\
\hline & $\mathrm{RR}$ & $95 \% \mathrm{Cl}$ & $P$ value & $\mathrm{RR}$ & $95 \% \mathrm{Cl}$ & $P$ value \\
\hline Age (year) & 1.03 & $0.99-1.06$ & 0.08 & 1.05 & $0.88-1.16$ & 0.25 \\
\hline Gender, male & 0.66 & $0.34-1.27$ & 0.21 & & & \\
\hline Mean BMI $\left(\mathrm{kg} / \mathrm{m}^{2}\right)$ & 1.17 & $1.06-1.28$ & $<0.01$ & 1.03 & $0.76-1.5$ & 0.87 \\
\hline CD4 + count nadir & 1.05 & $0.57-1.93$ & 0.19 & 1.6 & $0.44-5.05$ & 0.8 \\
\hline $\begin{array}{l}\text { Time of HIV infection } \\
\text { (months) }\end{array}$ & 1.005 & 1.001-1.009 & 0.01 & 1.001 & $0.98-1.014$ & 0.9 \\
\hline $\begin{array}{c}\text { Cumulative time on } \\
\text { HAART (months) }\end{array}$ & 1.007 & $1.002-1.012$ & 0.01 & 1.002 & $0.99-1.02$ & 0.75 \\
\hline $\begin{array}{l}\text { Time on current HAART } \\
\text { (months) }\end{array}$ & 1.006 & $0.99-1.019$ & 0.15 & 1.15 & $0.98-1.04$ & 0.3 \\
\hline Current use of PI & 2.32 & $1.24-4.44$ & $<0.01$ & 1.49 & $0.39-5.88$ & 0.56 \\
\hline HCV coinfection & 3.03 & $1.64-5.88$ & $<0.01$ & 2.19 & $0.57-8.34$ & 0.24 \\
\hline Vitamin D deficiency & 1.01 & $0.54-1.83$ & 0.9 & & & \\
\hline Waist (cm) & 1.08 & 1.04-1.12 & $<0.01$ & 1.04 & $0.92-1.17$ & 0.49 \\
\hline Waist/hip ratio & 12.8 & $1.5-19.1$ & $<0.01$ & 10 & $1.66-16$ & $<0.01$ \\
\hline Trunk fat (kg) & 1.07 & $1.004-1.14$ & 0.037 & 1.01 & $0.83-1.19$ & 0.9 \\
\hline Trunk fat (\%) & 1.08 & $1.04-1.13$ & $<0.01$ & 1.08 & 1.01-1.17 & 0.04 \\
\hline Total fat (\%) & 1.07 & $1.02-1.13$ & $<0.01$ & 1.05 & $0.88-1.13$ & 0.2 \\
\hline FMR & 3.18 & $1.7-6.06$ & $<0.01$ & 2.32 & $0.56-9.1$ & 0.2 \\
\hline
\end{tabular}

HAART, highly active antiretroviral therapy; PI, protease inhibitors; HCV, hepatitis C virus; FMR, fat mass ratio (defined in the text). Values with a $P$ value of $<0.2$ were included into the multivariate analysis. 


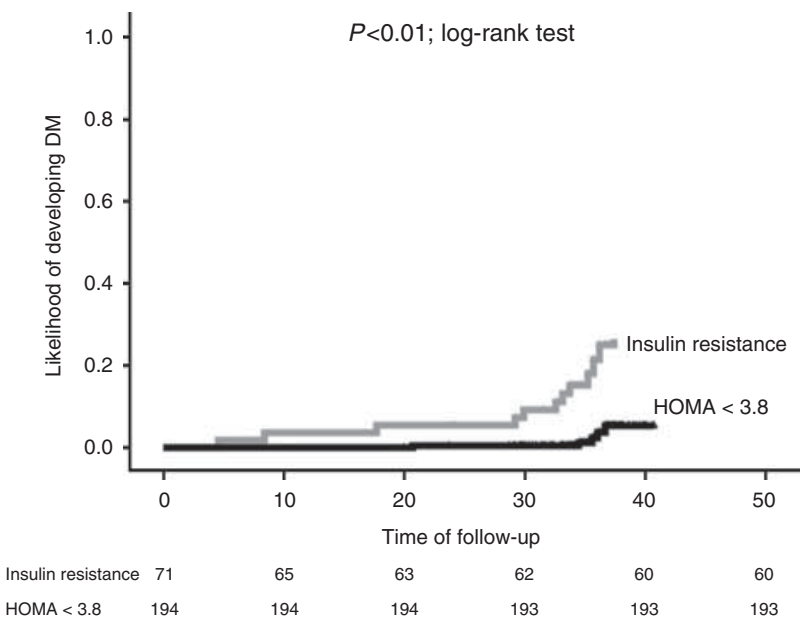

Figure 2

Kaplan-Meier estimates of diabetes mellitus during follow-up according to previous insulin resistance diagnosis (HOMA $\geq 3.8$ ).

follow-up), DM was observed in 8\% (22 patients), particularly in pretreated patients (4 vs $10 \%$, three and 19 patients respectively; $P=0.1$ ). Most of the cases were observed in patients with previous IR (17 vs $5 ; P<0.01)$. Thus, the overall rate of incident DM was 2.85 per 100 person-years, more than ten times higher in the case of previous IR (10.39 vs $0.82 / 100$ person-years; $P=0.01)$. In a Kaplan-Meier analysis, the 3-year estimate of incident DM was $7 \%$ higher in patients with IR (18 vs $2 \% ; P<0.01$; logrank test, Fig. 2). Also, at the end of follow-up, mean glucose was higher in patients with previous IR (100.1 vs $95.4 \mathrm{mg} / \mathrm{dl} ; P=0.05)$. At this time, $\mathrm{CD} 4+$ values were 593 cells $/ \mathrm{mm}^{3}$ (444-750), with a similar increase in patients with IR or not $(+161$ vs $+232 ; P=0.1)$, and $97 \%$ of patients had undetectable HIV RNA level.

\section{Discussion}

Our study, in a large cohort of patients in different lines of therapy, shows that the current prevalence of IR is $21 \%$, lower than previously published, which ranged from 35 to $63 \%(6,7)$. The prevalence in our study was similar to that seen in the general population, although there are significant differences by age, as it has been described in non-HIV controls older than 55-60 years (20).

More importantly, our study shows that there are two completely different HIV populations in terms of metabolic complications. Thus, the prevalence was $6 \%$ in patients receiving a first-line antiretroviral regimen, despite a median ART treatment time $>3$ years, and that certain antiretroviral drugs may cause IR for short time periods without alterations in body fat $(21,22)$. This rate is clearly lower than the $13 \%$ described by Palacios et al. in 2006 (23) in a similar population in our country after only a year on HAART and suggests a change in the risk of this complication for HIV patients starting current antiretroviral drugs.

This difference in prevalence could be due to several causes. First, HIV infection itself may influence the occurrence of IR. The mechanisms by which this occurs are not well understood, but if it is known that persistent immune activation and inflammation would contribute to the development of IR $(24,25)$. Indeed, in naïve patients, higher CD4 + lymphocyte count is associated with a lower evidence of IR $(8,24,26)$. Our current population started therapy with a higher nadir CD4+ count and less time of HIV infection, so favoring fewer metabolic alterations.

Second, there are changes in baseline patient characteristics, with fewer of our patients in first line having $\mathrm{HCV}$ coinfection. Hepatitis C coinfection has also been shown in some studies $(27,28)$, but not all studies $(29)$, to be associated with DM. In the first study with 1389 naive HIV patients, a relationship was found between coinfection and DM type 2, but not between coinfection and IR (4). In our current analysis, HCV was associated with a higher level of insulinemia and was a predictor of IR in the univariate analysis, albeit it was not related in the multivariate analysis.

But perhaps one of the most important factors to be evaluated is antiretroviral therapy, as it could be modified. Previously, multiple studies have described the relationship between IR and the use of HAART, particularly PIs and some NRTIs. It has been shown that some PIs such as lopinavir or indinavir increase insulinemia in healthy volunteers $(22,30,31)$, although it is debated whether this could be compensated in prolonged treatments (32). PIs could inhibit proteases responsible for conversion of proinsulin into insulin, as well as protease regulating insulin catabolism, generating a state of hyperinsulinemia and hyperglycemia (33). Another mechanism of action would be by reduction of the glucose transport mediated by the transporter glucose transporter protein 4 as shown by in vitro tests with drugs including indinavir, amprenavir, nelfinavir, and ritonavir $(34,35,36,37,38)$.

An increased risk of IR and DM has also been found to be associated with individual NRTIs, principally the thymidine analogues AZT and d4T that may directly increase lipolysis and consequently cause RI (11, 14, 15, 39, 40, 41). Among HIV-infected, cumulative exposure to NRTIs $>3$ years or to 
the NRTI d4T $>1$ year was associated with HOMA 1.15-fold higher $(15,42)$. Recent studies have suggested that genetically associated mitochondrial dysfunction is a major factor in IR and DM in the general population, and therefore, the development of IR and DM could be a result of mitochondrial dysfunction irrespective of whether the underlying cause is genetic or toxicity $(27,43)$.

Thus, hypothetically, the use of drugs with lower potential metabolic toxicity and not causing mitochondrial alteration as first-line treatment could decrease the risk of IR. Efavirenz, nevirapine, raltegravir, tenofovir, abacavir, and lamivudine have been associated with lower risk of mitochondrial toxicity, and low DM risk $(44,45,46)$. In addition, newer PI, especially atazanavir and darunavir, have been shown to have lower metabolic toxicity and to rarely cause IR $(47,48,49,50,51)$, a fact that could even explain the improvement of IR in pretreated patients switching to these drugs, as previously described with atazanavir, efavirenz, or nevirapine $(47,52)$. However, the cross-sectional inclusion of our patients precludes us to know whether lower IR found in pretreated patients is due to persistence of this complication or is the result of progressive decrease with the use of new drugs with a lower toxicity.

Our study including abdominal fat by DXA in all patients shows that IR is fundamentally associated with the abdominal fat accumulation/trunk obesity $(53,54)$, and not with antiretroviral therapy, HCV coinfection, vitamin D deficiency, CD4 + count nadir, or time of HIV infection. In fact, the amount of visceral fat is the main factor for IR and development of diabetes, together with age, in healthy patients, and previous studies linked closely truncal adiposity and increased waist-to-hip ratio with hyperinsulinemia and overt DM (55). Exposure to HAART may also lead to IR indirectly, through effects on regional body adipose tissue changes, inflammation and adipokine and free fatty acid dysregulation $(9,56)$. Indeed, fat abnormalities described in the lipodystrophy syndrome have been linked to IR and development of DM $(16,57)$. We observed a relation between cumulative time on HAART and some anthropometric measures, but neither current PI nor cumulative use explained in-depth fat changes and subsequent IR.

It has been observed that the risk of developing DM in HIV-positive patients receiving HAART was fourfold increased in comparison with HIV-negative patients in an observation period of 4 years (27). In our series, we found a 3 -year estimate of 7\% of developing DM for patients with IR at inclusion, but time from the onset of IR to DM cannot be clearly established as it is not known how long patients had IR previously. Of note, the observed rate of 2.85 per 100 person-years is slightly higher than that observed in seronegative controls in the MACS cohort (1.4 per 100 person-years), clearly lower to that described in patients receiving HAART before 2005 (4.7 per 100 person-years), and similar to that described in women in the WIHS cohort $(2.8)(27,58)$. Surprisingly, the DAD study found a crude incidence of new DM of 4.2 per 1000 person-years during a follow-up of 5.2 years, similar to that described in the Swiss cohort (4.6 per 1000 person-years) $(29,59)$. Although race, sex, BMI, and other baseline characteristics such as HAART exposure could be different, both studies are based on a large number of patients in different situations with prolonged exposure. In any case, the rate in our patients without IR receiving HAART, 8.2 per 1000 person-years is more similar to that observed in these large cohorts.

Among the limitations of our study, the most significant is the diagnosis of incident DM by confirmed fasting glucose above $126 \mathrm{mg} / \mathrm{dl}$, and not by oral glucose tolerance test, a fact that could have delayed the time to diagnosis. On the other hand, it reflects the clinical management of patients. Also, information regarding other important risk factors for IR or DM (e.g. family history, physical inactivity) was not collected, but in contrast, no patient received during the study any drugs associated with worsening IR or DM, such as niacin, megestrol acetate, steroids, or thiazides. Finally, follow-up could be not long enough to adequately show the rate of DM, taking into account the influence of aging. However, the previous studies had a similar follow-up, and even longer exposure times with few new cases of DM could lead to a lower incidence rate, as observed in large cohorts.

In conclusion, current prevalence of IR in HIV patients appears to be lower than previously reported, and it is primarily associated with accumulation of abdominal fat, as described in the general population. We found a 3-year estimate risk of $7 \%$ for developing DM in patients with IR, supporting the importance of regular screening for hyperglycemia among HIV-infected persons, especially in largely pretreated patients with increased abdominal fat. On the other hand, our study confirms the low risk of IR in recently diagnosed HIV patients receiving current antiretroviral drugs, and it suggests a progressive decrease for this complication in this high-risk population.

Declaration of interest

The authors declare that there is no conflict of interest that could be perceived as prejudicing the impartiality of the research reported. 


\section{Funding}

This research did not receive any specific grant from any funding agency in the public, commercial, or not-for-profit sector.

\section{Author contribution statement}

$S$ Araujo and J L Casado conceived and designed the study and were responsible for patient enrollment, data analysis and drafted and finalized the article; S Bañón, I Machuca, M J Pérez-Elías, and A Moreno were responsible for patient enrollment, clinically followed up patients, and helped to write the work. All coauthors revised the manuscript and read and approved the final version.

\section{Acknowledgements}

The authors would like to thank Ana Abad for their important contribution in database management.

\section{References}

1 Collaboration of Observational HIV Epidemiological Research Europe (COHERE) in EuroCoord, Lewden C, Bouteloup V, De Wit S, Sabin C, Mocroft A, Wasmuth JC, van Sighem A, Kirk O, Obel N et al. All-cause mortality in treated HIV-infected adults with CD4 $\geq 500 / \mathrm{mm} 3$ compared with the general population: evidence from a large European observational cohort collaboration. International Journal of Epidemiology 201241 433-445. (doi:10.1093/ije/dyr164)

2 Guaraldi G, Orlando G, Zona S, Menozzi M, Carli F, Garlassi E, Berti A, Rossi E, Roverato A \& Palella F. Premature age-related comorbidities among HIV-infected persons compared with the general population. Clinical Infectious Diseases 201153 1120-1126. (doi:10.1093/cid/cir627)

3 Calmy A, Hirschel B, Cooper DA \& Carr A. Clinical update: adverse effects of antiretroviral therapy. Lancet 2007370 12-14. (doi:10.1016/ S0140-6736(07)61027-7)

4 Visnegarwala F, Chen L, Raghavan S \& Tedaldi E. Prevalence of diabetes mellitus and dyslipidemia among antiretroviral naive patients co-infected with hepatitis C virus (HCV) and HIV-1 compared to patients without co-infection. Journal of Infection 200550 331-337. (doi:10.1016/j.jinf.2004.06.001)

5 Capeau J, Bouteloup V, Katlama C, Bastard JP, Guiyedi V, SalmonCeron D, Protopopescu C, Leport C, Raffi F, Chene G et al. Ten-year diabetes incidence in $1046 \mathrm{HIV}$-infected patients started on a combination antiretroviral treatment. AIDS 201226 303-314. (doi:10.1097/QAD.0b013e32834e8776)

6 Samaras K. Prevalence and pathogenesis of diabetes mellitus in HIV-1 infection treated with combined antiretroviral therapy. Journal of Acquired Immune Deficiency Syndromes 200950 499-505. (doi:10.1097/ QAI.0b013e31819c291b)

7 Arama V, Tiliscan C, Streinu-Cercel A, Ion D, Mihailescu R, Munteanu D, Hristea A, Arama SS \& group S-As . Insulin resistance and adipokines serum levels in a caucasian cohort of HIV-positive patients undergoing antiretroviral therapy: a cross sectional study. $B M C$ Endocrine Disorder 201313 4. (doi:10.1186/1472-6823-13-4)

8 Boufassa F, Goujard C, Viard JP, Carlier R, Lefebvre B, Yeni P, Bouchaud O, Capeau J, Meyer L, Vigouroux C et al. Immune deficiency could be an early risk factor for altered insulin sensitivity in antiretroviral-naive HIV-1-infected patients: the ANRS COPANA cohort. Antiviral Therapy 201217 91-100. (doi:10.3851/IMP1916)

9 Calza L, Manfredi R \& Chiodo F. Insulin resistance and diabetes mellitus in HIV-infected patients receiving antiretroviral therapy. Metabolic Syndrome and Related Disorders 20042 241-250. (doi:10.1089/met.2004.2.241)
10 Addy CL, Gavrila A, Tsiodras S, Brodovicz K, Karchmer AW \& Mantzoros CS. Hypoadiponectinemia is associated with insulin resistance, hypertriglyceridemia, and fat redistribution in human immunodeficiency virus-infected patients treated with highly active antiretroviral therapy. Journal of Clinical Endocrinology and Metabolism 200388 627-636. (doi:10.1210/jc.2002-020795)

11 Blumer RM, van Vonderen MG, Sutinen J, Hassink E, Ackermans M, van Agtmael MA, Yki-Jarvinen H, Danner SA, Reiss P \& Sauerwein HP. Zidovudine/lamivudine contributes to insulin resistance within 3 months of starting combination antiretroviral therapy. AIDS 200822 227-236. (doi:10.1097/QAD.0b013e3282f33557)

12 Dave JA, Lambert EV, Badri M, West S, Maartens G \& Levitt NS. Effect of nonnucleoside reverse transcriptase inhibitor-based antiretroviral therapy on dysglycemia and insulin sensitivity in South African HIV-infected patients. Journal of Acquired Immune Deficiency Syndromes 201157 284-289. (doi:10.1097/QAI.0b013e318221863f)

13 Duong M, Petit JM, Piroth L, Grappin M, Buisson M, Chavanet P, Hillon P \& Portier H. Association between insulin resistance and hepatitis $\mathrm{C}$ virus chronic infection in HIV-hepatitis $\mathrm{C}$ virus-coinfected patients undergoing antiretroviral therapy. Journal of Acquired Immune Deficiency Syndromes 200127 245-250. (doi:10.1097/00126334200107010-00005)

14 van Vonderen MG, Blumer RM, Hassink EA, Sutinen J, Ackermans MT, van Agtmael MA, Yki-Jarvinen H, Danner SA, Serlie MJ, Sauerwein HP et al. Insulin sensitivity in multiple pathways is differently affected during zidovudine/lamivudine-containing compared with NRTI-sparing combination antiretroviral therapy. Journal of Acquired Immune Deficiency Syndromes 201053 186-193. (doi:10.1097/QAI. Ob013e3181c190f4)

15 Tien PC, Schneider MF, Cole SR, Levine AM, Cohen M, DeHovitz J, Young M \& Justman JE. Antiretroviral therapy exposure and insulin resistance in the Women's Interagency HIV study. Journal of Acquired Immune Deficiency Syndromes 200849 369-376. (doi:10.1097/QAI. Ob013e318189a780)

16 Freitas P, Carvalho D, Santos AC, Mesquita J, Matos MJ, Madureira AJ, Martinez E, Sarmento A \& Medina JL. Lipodystrophy defined by fat mass ratio in HIV-infected patients is associated with a high prevalence of glucose disturbances and insulin resistance. BMC Infectious Diseases 201212 180. (doi:10.1186/1471-2334-12-180)

17 Matthews DR, Hosker JP, Rudenski AS, Naylor BA, Treacher DF \& Turner RC. Homeostasis model assessment: insulin resistance and $\beta$-cell function from fasting plasma glucose and insulin concentrations in man. Diabetologia 198528 412-419. (doi:10.1007/BF00280883)

18 Bonora E, Targher G, Alberiche M, Bonadonna RC, Saggiani F, Zenere MB, Monauni T \& Muggeo M. Homeostasis model assessment closely mirrors the glucose clamp technique in the assessment of insulin sensitivity: studies in subjects with various degrees of glucose tolerance and insulin sensitivity. Diabetes Care 200023 57-63. (doi:10.2337/diacare.23.1.57)

19 Nathan DM, Buse JB, Davidson MB, Heine RJ, Holman RR, Sherwin R \& Zinman B. Management of hyperglycemia in type 2 diabetes: a consensus algorithm for the initiation and adjustment of therapy: a consensus statement from the American Diabetes Association and the European Association for the Study of Diabetes. Diabetes Care 200629 1963-1972. (doi:10.2337/dc06-9912)

20 Marques-Vidal P, Mazoyer E, Bongard V, Gourdy P, Ruidavets JB, Drouet L \& Ferrieres J. Prevalence of insulin resistance syndrome in southwestern France and its relationship with inflammatory and hemostatic markers. Diabetes Care 200225 1371-1377. (doi:10.2337/ diacare.25.8.1371)

21 Ben-Romano R, Rudich A, Torok D, Vanounou S, Riesenberg K, Schlaeffer F, Klip A \& Bashan N. Agent and cell-type specificity in the induction of insulin resistance by HIV protease inhibitors. AIDS 2003 17 23-32. (doi:10.1097/00002030-200301030-00005)

22 Lee GA, Lo JC, Aweeka F, Schwarz JM, Mulligan K, Schambelan M \& Grunfeld C. Single-dose lopinavir-ritonavir acutely inhibits 
insulin-mediated glucose disposal in healthy volunteers. Clinical Infectious Diseases 200643 658-660. (doi:10.1086/505974)

23 Palacios R, Merchante N, Macias J, Gonzalez M, Castillo J, Ruiz J, Marquez M, Gomez-Mateos J, Pineda JA \& Santos J. Incidence of and risk factors for insulin resistance in treatment-naive HIV-infected patients 48 weeks after starting highly active antiretroviral therapy. Antiviral Therapy 200611 529-535.

24 El-Sadr WM, Mullin CM, Carr A, Gibert C, Rappoport C, Visnegarwala F, Grunfeld C \& Raghavan SS. Effects of HIV disease on lipid, glucose and insulin levels: results from a large antiretroviral-naive cohort. HIV Medicine 20056 114-121. (doi:10.1111/j.1468-1293.2005.00273.x)

25 Brown TT, Tassiopoulos K, Bosch RJ, Shikuma C \& McComsey GA. Association between systemic inflammation and incident diabetes in HIV-infected patients after initiation of antiretroviral therapy. Diabetes Care 201033 2244-2249. (doi:10.2337/dc10-0633)

26 Limone P, Biglino A, Valle M, Degioanni M, Paola Servato M, Berardi C, Del Rizzo P, Pellissetto C \& Carlo Isaia G. Insulin resistance in HIVinfected patients: relationship with pro-inflammatory cytokines released by peripheral leukocytes. Journal of Infection 2003 47 52-58. (doi:10.1016/S0163-4453(03)00055-0)

27 Brown TT, Cole SR, Li X, Kingsley LA, Palella FJ, Riddler SA, Visscher BR, Margolick JB \& Dobs AS. Antiretroviral therapy and the prevalence and incidence of diabetes mellitus in the multicenter AIDS cohort study. Archives of Internal Medicine 2005165 1179-1184. (doi:10.1001/ archinte.165.10.1179)

28 Butt AA, Fultz SL, Kwoh CK, Kelley D, Skanderson M \& Justice AC. Risk of diabetes in HIV infected veterans pre- and post-HAART and the role of HCV coinfection. Hepatology 200440 115-119. (doi:10.1002/hep.20289)

29 Ledergerber B, Furrer H, Rickenbach M, Lehmann R, Elzi L, Hirschel B, Cavassini M, Bernasconi E, Schmid P, Egger M et al. Factors associated with the incidence of type 2 diabetes mellitus in HIV-infected participants in the Swiss HIV Cohort Study. Clinical Infectious Diseases 200745 111-119. (doi:10.1086/518619)

30 Lee GA, Seneviratne T, Noor MA, Lo JC, Schwarz JM, Aweeka FT, Mulligan K, Schambelan M \& Grunfeld C. The metabolic effects of lopinavir/ritonavir in HIV-negative men. AIDS 200418 641-649. (doi:10.1097/00002030-200403050-00008)

31 Schwarz JM, Lee GA, Park S, Noor MA, Lee J, Wen M, Lo JC, Mulligan K, Schambelan M \& Grunfeld C. Indinavir increases glucose production in healthy HIV-negative men. AIDS 200418 1852-1854. (doi:10.1097/ 00002030-200409030-00017)

32 Hruz PW, Murata H, Qiu H \& Mueckler M. Indinavir induces acute and reversible peripheral insulin resistance in rats. Diabetes $2002 \mathbf{5 1}$ 937-942. (doi:10.2337/diabetes.51.4.937)

33 Walli R, Herfort O, Michl GM, Demant T, Jager H, Dieterle C, Bogner JR, Landgraf R \& Goebel FD. Treatment with protease inhibitors associated with peripheral insulin resistance and impaired oral glucose tolerance in HIV-1-infected patients. AIDS 199812 F167-F173. (doi:10.1097/ 00002030-199815000-00001)

34 Jain RG, Furfine ES, Pedneault L, White AJ \& Lenhard JM. Metabolic complications associated with antiretroviral therapy. Antiviral Research 200151 151-177. (doi:10.1016/S0166-3542(01)00148-6)

35 Janneh O, Hoggard PG, Tjia JF, Jones SP, Khoo SH, Maher B, Back DJ \& Pirmohamed M. Intracellular disposition and metabolic effects of zidovudine, stavudine and four protease inhibitors in cultured adipocytes. Antiviral Therapy 20038 417-426.

36 Behrens G, Dejam A, Schmidt H, Balks HJ, Brabant G, Korner T, Stoll M $\&$ Schmidt RE. Impaired glucose tolerance, $\beta$ cell function and lipid metabolism in HIV patients under treatment with protease inhibitors. AIDS 199913 F63-F70. (doi:10.1097/00002030-199907090-00001)

37 Carper MJ, Cade WT, Cam M, Zhang S, Shalev A, Yarasheski KE \& Ramanadham S. HIV-protease inhibitors induce expression of suppressor of cytokine signaling-1 in insulin-sensitive tissues and promote insulin resistance and type 2 diabetes mellitus. American Journal of Physiology. Endocrinology and Metabolism 2008294 E558-E567. (doi:10.1152/ajpendo.00167.2007)
38 Cheng M, Chen S, Schow SR, Manchem VP, Spevak WR, Cristobal CP, Shi S, Macsata RW, Lum RT, Goldfine ID et al. In vitro and in vivo prevention of HIV protease inhibitor-induced insulin resistance by a novel small molecule insulin receptor activator. Journal of Cellular Biochemistry 200492 1234-1245. (doi:10.1002/jcb.20150)

39 Woerle HJ, Mariuz PR, Meyer C, Reichman RC, Popa EM, Dostou JM, Welle SL \& Gerich JE. Mechanisms for the deterioration in glucose tolerance associated with HIV protease inhibitor regimens. Diabetes 200352 918-925. (doi:10.2337/diabetes.52.4.918)

40 Yan Q \& Hruz PW. Direct comparison of the acute in vivo effects of HIV protease inhibitors on peripheral glucose disposal. Journal of Acquired Immune Deficiency Syndromes 200540 398-403. (doi:10.1097/01.qai. 0000176654.97392.c7)

41 Brown TT, Li X, Cole SR, Kingsley LA, Palella FJ, Riddler SA, Chmiel JS, Visscher BR, Margolick JB \& Dobs AS. Cumulative exposure to nucleoside analogue reverse transcriptase inhibitors is associated with insulin resistance markers in the Multicenter AIDS Cohort Study. AIDS 200519 1375-1383. (doi:10.1097/01.aids.0000181011.62385.91)

42 Fleischman A, Johnsen S, Systrom DM, Hrovat M, Farrar CT, Frontera W, Fitch K, Thomas BJ, Torriani M, Cote HC et al. Effects of a nucleoside reverse transcriptase inhibitor, stavudine, on glucose disposal and mitochondrial function in muscle of healthy adults. American Journal of Physiology. Endocrinology and Metabolism 2007292 E1666-E1673. (doi:10.1152/ajpendo.00550.2006)

43 Morino K, Petersen KF, Dufour S, Befroy D, Frattini J, Shatzkes N, Neschen S, White MF, Bilz S, Sono S et al. Reduced mitochondrial density and increased IRS-1 serine phosphorylation in muscle of insulin-resistant offspring of type 2 diabetic parents. Journal of Clinical Investigation 2005115 3587-3593. (doi:10.1172/JCI25151)

44 Randell PA, Jackson AG, Zhong L, Yale K \& Moyle GJ. The effect of tenofovir disoproxil fumarate on whole-body insulin sensitivity, lipids and adipokines in healthy volunteers. Antiviral Therapy 201015 227-233. (doi:10.3851/IMP1518)

45 Bernal E, Masia M, Padilla S, Ramos JM, Martin-Hidalgo A \& Gutierrez F. Insulin resistance in HIV-infected patients receiving long-term therapy with efavirenz, lopinavir/ritonavir and atazanavir. Medicina Cĺnica 2007 129 252-254. (doi:10.1157/13108348)

46 Shlay JC, Visnegarwala F, Bartsch G, Wang J, Peng G, El-Sadr WM, Gibert C, Kotler D, Grunfeld C, Raghavan S et al. Body composition and metabolic changes in antiretroviral-naive patients randomized to didanosine and stavudine vs. abacavir and lamivudine. Journal of Acquired Immune Deficiency Syndromes 200538 147-155. (doi:10.1097/ 01.qai.0000143599.64234.15)

47 Busti AJ, Bedimo R, Margolis DM \& Hardin DS. Improvement in insulin sensitivity and dyslipidemia in protease inhibitor-treated adult male patients after switch to atazanavir/ritonavir. Journal of Investigative Medicine 200856 539-544. (doi:10.231/JIM.0b013e3181641b26)

48 Capel E, Auclair M, Caron-Debarle M \& Capeau J. Effects of ritonavirboosted darunavir, atazanavir and lopinavir on adipose functions and insulin sensitivity in murine and human adipocytes. Antiviral Therapy 201217 549-556. (doi:10.3851/IMP1988)

49 Noor MA, Parker RA, O'Mara E, Grasela DM, Currie A, Hodder SL, Fiedorek FT \& Haas DW. The effects of HIV protease inhibitors atazanavir and lopinavir/ritonavir on insulin sensitivity in HIVseronegative healthy adults. AIDS 200418 2137-2144. (doi:10.1097/ 00002030-200411050-00005)

50 Aberg JA, Tebas P, Overton ET, Gupta SK, Sax PE, Landay A, Falcon R, Ryan R \& De La Rosa G. Metabolic effects of darunavir/ritonavir versus atazanavir/ritonavir in treatment-naive, HIV type 1-infected subjects over 48 weeks. AIDS Research and Human Retroviruses 201228 1184-1195. (doi:10.1089/aid.2011.0327)

51 Tomaka F, Lefebvre E, Sekar V, Van Baelen B, Vangeneugden T, Vandevoorde A \& Diego Miralles G. Effects of ritonavir-boosted darunavir vs. ritonavir-boosted atazanavir on lipid and glucose parameters in HIV-negative, healthy volunteers. HIV Medicine 200910 318-327. (doi:10.1111/j.1468-1293.2008.00690.x) 
52 Tebas P, Yarasheski K, Henry K, Claxton S, Kane E, Bordenave B, Klebert M \& Powderly WG. Evaluation of the virological and metabolic effects of switching protease inhibitor combination antiretroviral therapy to nevirapine-based therapy for the treatment of HIV infection. AIDS Research and Human Retroviruses 200420 589-594. (doi:10.1089/ 0889222041217374)

53 Albu JB, Kenya S, He Q, Wainwright M, Berk ES, Heshka S, Kotler DP \& Engelson ES. Independent associations of insulin resistance with high whole-body intermuscular and low leg subcutaneous adipose tissue distribution in obese HIV-infected women. American Journal of Clinical Nutrition 200786 100-106.

54 Blass SC, Ellinger S, Vogel M, Ingiliz P, Spengler U, Stehle P, von Ruecker A \& Rockstroh JK. Overweight HIV patients with abdominal fat distribution treated with protease inhibitors are at high risk for abnormalities in glucose metabolism - a reason for glycemic control. European Journal of Medical Research 200813 209-214.

55 Preis SR, Massaro JM, Robins SJ, Hoffmann U, Vasan RS, Irlbeck T, Meigs JB, Sutherland P, D'Agostino RB Sr, O'Donnell CJ et al. Abdominal subcutaneous and visceral adipose tissue and insulin resistance in the Framingham heart study. Obesity 201018 2191-2198. (doi:10.1038/oby.2010.59)
56 Lenhard JM, Furfine ES, Jain RG, Ittoop O, Orband-Miller LA, Blanchard SG, Paulik MA \& Weiel JE. HIV protease inhibitors block adipogenesis and increase lipolysis in vitro. Antiviral Research 200047 121-129. (doi:10.1016/S0166-3542(00)00102-9)

57 Estrada V, Martinez-Larrad MT, Gonzalez-Sanchez JL, de Villar NG, Zabena C, Fernandez C \& Serrano-Rios M. Lipodystrophy and metabolic syndrome in HIV-infected patients treated with antiretroviral therapy. Metabolism 200655 940-945. (doi:10.1016/j.metabol.2006. 02.024)

58 Justman JE, Benning L, Danoff A, Minkoff H, Levine A, Greenblatt RM, Weber K, Piessens E, Robison E \& Anastos K. Protease inhibitor use and the incidence of diabetes mellitus in a large cohort of HIV-infected women. Journal of Acquired Immune Deficiency Syndromes 200332 298-302. (doi:10.1097/00126334200303010-00009)

59 Petoumenos K, Worm SW, Fontas E, Weber R, De Wit S, Bruyand M, Reiss P, El-Sadr W, Monforte AD, Friis-Moller N et al. Predicting the short-term risk of diabetes in HIV-positive patients: the Data Collection on Adverse Events of Anti-HIV Drugs (D:A:D) study. Journal of the International AIDS Society 201215 17426. (doi:10.7448/IAS. 15.2.17426)

Received 26 April 2014

Revised version received 20 July 2014

Accepted 6 August 2014 